\title{
Patients' perceptions of GP non-verbal communication: a qualitative study
}

\author{
Ludmila Marcinowicz, Jerzy Konstantynowicz and Cezary Godlewski
}

\author{
ABSTRACT

\section{Background} \\ During doctor-patient interactions, many messages are \\ transmitted without words, through non-verbal \\ communication. \\ Aim \\ To elucidate the types of non-verbal behaviours \\ perceived by patients interacting with family GPs and \\ to determine which cues are perceived most frequently. \\ Design of study \\ In-depth interviews with patients of family GPs. \\ Setting \\ Nine family practices in different regions of Poland.

\section{Method} \\ At each practice site, interviews were performed with \\ four patients who were scheduled consecutively to see \\ their family doctor.

\section{Results} \\ Twenty-four of 36 studied patients spontaneously \\ perceived non-verbal behaviours of the family GP \\ during patient-doctor encounters. They reported a total \\ of 48 non-verbal cues. The most frequent features \\ were tone of voice, eye contact, and facial \\ expressions. Less frequent were examination room \\ characteristics, touch, interpersonal distance, GP \\ clothing, gestures, and posture.

\section{Conclusion} \\ Non-verbal communication is an important factor by \\ which patients spontaneously describe and evaluate \\ their interactions with a GP. Family GPs should be \\ trained to better understand and monitor their own \\ non-verbal behaviours towards patients.

\section{Keywords} \\ doctor-patient relations; evaluation; non-verbal \\ communication; qualitative research.
}

\section{INTRODUCTION}

Communication skills, in addition to medical knowledge, problem-solving ability, and thorough physical examination, are essential components of good clinical practice. ${ }^{1}$ Communication is also an important domain of the patient-centred approach from the patient's perspective. ${ }^{2,3}$ Roter et al suggest that expression of emotion during medical visits is especially related to non-verbal communication. ${ }^{4} \mathrm{~A}$ review of the literature shows that non-verbal behaviour of doctors is a significant factor in patient satisfaction, adherence, and clinical outcome. ${ }^{4-6}$ Medical students are educated about the importance of appropriate non-verbal behaviours for building successful doctor-patient relationships. ${ }^{1}$ In addition to understanding non-verbal cues from patients, GPs must understand how their own non-verbal behaviours may be interpreted by patients. ${ }^{7}$

Non-verbal communication is the subject of an increasing number of medical literature reports; however, many authors suggest that research regarding non-verbal communication has been neglected and requires further exploration. ${ }^{4,8,9}$

Non-verbal communication refers to communication without linguistic content. ${ }^{10}$ In the present study, non-verbal communication was conceptualised as being composed of nine elements:

L Marcinowicz; RN, MA, PhD, lecturer, Department of Family Medicine and Community Nursing; J Konstantynowicz; MD, PhD, assistant professor, Department of Pediatrics and Developmental Disorders; C Godlewski, MPsych, PhD, senior lecturer and Polish Psychological Association certified psychotherapist, Department of Philosophy and Psychology, Medical University of Bialystok, Poland.

Address for correspondence

Ludmila Marcinowicz, Medical University of Bialystok, Department of Family Medicine and Community Nursing, Mieszka I 4 B, Bialystok, 15 054, Poland. E-mail: ludmila.marcinowicz@umwb.edu.pl

Submitted: 19 May 2009; Editor's response: 21 July 2009; final acceptance: 5 August 2009.

(0)British Journal of General Practice 2010; 60: 83-87.

DOI: 10.3399/bjgp10X483111 


\section{How this fits in}

Communication skills, in addition to medical knowledge, problem-solving ability, and thorough physical examination, are essential components of good clinical practice. A review of the literature shows that GP non-verbal behaviour is a significant factor in patient satisfaction, adherence, and clinical outcome. In this study, it was found that non-verbal communication is an important factor by which patients evaluate their interactions with GPs. This study's results indicate that patients are sensitive to several non-verbal GP behaviours that can be interpreted positively or negatively.

eye contact, facial expressions, touch, interpersonal distance, gestures, posture, tone of voice, GP dress, and examination room characteristics. ${ }^{1,10,11}$ While technically tone of voice is a non-verbal signal, more commonly it is described as a paralinguistic feature..$^{4,11}$

The present study aimed to elucidate the types of non-verbal communication spontaneously perceived by patients interacting with their GPs and to determine which behaviours are perceived most frequently.

\section{METHOD}

\section{Study design and setting}

Using a qualitative research design approach, indepth interviews with patients of GPs were conducted. A total of 36 participants, four patients from each of nine family practices in different regions of Poland, were interviewed. Purposive sampling was used to maximise variation in the data, including type of practice (small or large) and locale (urban - large or small towns; or rural areas). ${ }^{12,13}$ At each practice site, interviews were performed with four patients who were scheduled consecutively to see their GP.

This study is a secondary data analysis of 36 transcripts of in-depth interviews with patients. The main aim of this qualitative study was to explore the concept of satisfaction from the perspective of patients receiving care from GPs, firstly by

Table 1. Participant characteristics $(n=36)$.

\begin{tabular}{lcc} 
& $\begin{array}{c}\text { Participants who perceived } \\
\text { non-verbal behaviours } \\
n=24\end{array}$ & $\begin{array}{c}\text { Participants who did not } \\
\text { perceive non-verbal behaviours } \\
n=12\end{array}$ \\
Characteristics & $53(20-78)$ & $58(43-76)$ \\
\hline Mean age, years (range) & & 6 \\
\hline Sex, $n$ & 14 & 6 \\
Female & 10 & 1 \\
Male & & 2 \\
\hline Education, $n$ & 4 & 8 \\
Elementary & 2 & 1 \\
Technical & 8 & 10 \\
Secondary & 10 & 2 \\
University & & \\
\hline Chronic health condition, $n$ & 15 & \\
Yes & 9 & \\
No & & \\
\hline
\end{tabular}

investigating the possibility of characterising the patients' responses typologically, considering patient evaluations of health care, and secondly by identifying the particular healthcare dimensions that determine patient satisfaction. ${ }^{14}$

\section{Data collection}

Data were collected by interviewing patients using an unstructured interview schedule.

Open-ended interview questions included:

- 'What are your experiences with the use of family doctor services?'

- 'What does it mean to you to be satisfied with the visit at the family doctor?'

- 'Have you experienced any particularly dissatisfying situations?'

- 'What was your last visit to the family doctor like?'.

Responders were invited to participate in the study after their medical consultation. All interviews were conducted by the first author and lasted between 25 minutes and 2.5 hours. Some interviews were carried out on the day of the consultation, and all interviews were completed within 1 week of the invitation. In-depth interviews were conducted between May 2007 and January 2008. All interviews were tape-recorded and transcribed in full.

\section{Data analysis}

The data were analysed using thematic analysis. ${ }^{12}$ First, two authors from different professional backgrounds (primary care and psychology) read the transcripts carefully, line-by-line. Next, all themes related to non-verbal cues were noted in the margins, using standard manual qualitative techniques of open coding. In the second stage, the themes were grouped into mutually exclusive categories, which were compared with those reported elsewhere in the literature. Two researchers analysed the data independently and any discrepancies were resolved through discussion. ${ }^{13}$ The quotes used in this study reflected the most typical comments of participants.

\section{RESULTS}

From a total of 36 participants, 12 made no reported spontaneous observations at all about non-verbal communication, while 24 participants spontaneously perceived non-verbal behaviours of their GPs during doctor-patient encounters. Demographic characteristics for both categories of participant are presented in Table 1. The mean age of participants who perceived non-verbal behaviour of their GPs was lower than that of those who did not (53 versus 58 years), and the former tended to have higher levels of formal education than the latter. 
In total, 48 non-verbal behaviours were spontaneously perceived: tone of voice, $n=12$; eye contact, $n=10$; facial expression, $n=8$; examination room characteristics, $n=6$; touch, $n=5$; interpersonal distance, $n=3$; GP dress, $n=2$; GP gestures, $n=1$; and GP posture, $n=1$. Thirteen participants noted only one non-verbal cue, nine patients named two cues, and two patients reported three cues.

\section{Tone of voice}

The most frequently perceived cue was GP tone of voice. Participants noted positive and negative nonverbal signals. For example, one participant noted that: 'the doctor speaks nicely to me' (interview 24). Another participant recalled that the doctor: 'shouted at me and it was so unpleasant' (interview 35). Another one stated:

'At the beginning of the visit I unexpectedly heard loud, coarse words being uttered by the doctor, which surprised me greatly.' (interview 6)

\section{Eye contact}

Eye contact was the second most frequently perceived non-verbal signal. Some participants measured GP interest and commitment by eye contact, stating that:

'You can feel [the personal attention by] how someone looks into your eyes, not making any notes or writing on a computer at that time; I can see the interest.' (interview 27)

\section{Another participant noted that:}

'You can see it from the doctor's eyes that he cares and is involved.' (interview 2)

Other participants associated eye contact with a sense of being heard or understood:

'Such as eye contact. You can see that the doctor is listening. Listening and looking at you.' (interview 30)

Participants perceived GPs' lack of eye contact as a sign of inattention. One participant responded that the GP:

'... did not look at me or touch me. Just mechanical bashing out [on the computer].' (interview 4)

\section{Facial expressions}

Regarding GP facial expressions, participants most often perceived smiles or lack thereof. One participant noted that: 'she always smiles when providing patient care' (interview 22). Some participants noticed more subtle details, indicating careful observation of the GP's facial expression. For example, one participant said of their GP:

'You can see at once that he is moved by what I say. You can see it all over his face. That is, you say, the tiniest things seem to speak.' (interview 8)

\section{Examination room characteristics}

Participants perceived examination room characteristics, including the presence of photographs and office decor. The presence of family photos positively influenced patients' perception of their GPs. One participant noted:

'The family photos. That is, I know the doctor's daughter. There may be a lot more different things there, but when there is a photo, it means he is a family man. This is nice, such a tiny thing. And whenever I sit there, I don't know why, I always look at these photos.' (interview 25)

Participants also noted colours and decorations in the GP's office. One participant recalled that:

'There is an eye examination chart and it is colourful. And there is a flower.' (interview 26)

Decoration of the patient area was also appreciated:

'There are newspapers on the table; you can read something while waiting to go in.' (interview 28)

\section{Touch}

Touch was seldom perceived or described by participants. Some participants provided simple, positive assessments of GP greeting gestures. For example, one participant noted that the: 'doctor greets me ... we shake hands' (interview 29). Other participants unhappily noted a lack of touch:

'This doctor, as if he never touched a patient; even not raising his head ... No touching, nothing.' (interview 32)

\section{Interpersonal distance}

Three participants perceived interpersonal distance between themselves and their healthcare providers. One participant negatively described non-verbal cues from her GP, who: 'is sitting here, one desk, a computer, me there at the door and my husband sitting at another desk' (interview 3). Another participant noted an inappropriately impersonal nonverbal behaviour during registration: 
'Here, there is a nurse and you can talk to her, but there [referring to another practice], there is a small window at reception and when I came in I looked over and the nurse were sitting somewhere in the back.' (interview 20).

\section{GP dress}

For some participants, the GP's lack of a white coat was perceived as positive for the doctor-patient interaction:

'There are no typical coats that would be strongly associated with a medical institution ... Here the doctor has a normal outfit. This is a white or coloured shirt, a tie; much nicer for me.' (interview 26)

\section{Gestures and posture}

Gestures and posture conveying an unhurried attitude were noted by two participants. One participant was pleased that the: 'doctor does not look at a watch, is not impatient' (interview 20). Another participant noted that the GP's relaxed posture contributed positively to the doctor-patient interaction:

'[The] doctor is not stiff in his manner, never sitting behind the desk or looking only from the doctor's position; he will sometimes sit comfortably, open a book when looking for a medicine; he looks casual, not stressed by the patient's visit; you can sit down and talk ... In this way, the talk is more personal.' (interview 25)

\section{DISCUSSION}

\section{Summary of main findings}

This study's results indicate that patients are sensitive to several non-verbal GP behaviours that can be interpreted positively or negatively. However, such non-verbal cues as gestures, body position, GP dress, and room decor were perceived by few patients, suggesting individual differences in perception of GPs' non-verbal behaviour. These data also suggest that younger patients and those with a university education most frequently perceive non-verbal behaviour of their GPs during doctor-patient encounters.

Although the less educated patients made fewer spontaneous observations, this was probably not because they were less influenced by non-verbal behaviours but more likely because they are less accustomed to expressing analytical observations.

\section{Strengths and limitations of the study}

The strength of the study is the use of in-depth interviews to elucidate the types of non-verbal cues perceived by patients interacting with their GPs. In their spontaneous utterances, the responders gave detailed information about the non-verbal behaviour of the GP. ${ }^{15} \mathrm{~A}$ weakness of the secondary data analysis is that comments/answers were only collected from those participants who spontaneously expressed their opinions on the topic. The study findings are limited by the small number of patients who spontaneously perceived their GPs' non-verbal behaviour. Nonetheless, this limitation is true of most qualitative studies employing in-depth interviews, and there is much information to gain by this type of research design. The most important is the quality of the information collected. ${ }^{16}$

\section{Comparison with existing literature}

The finding that tone of voice was the non-verbal cue most frequently perceived by patients is supported by previous findings. ${ }^{17}$ Recently, Haskard et al conducted a detailed examination of voice tone in doctor-patient and nurse-patient primary-care medical visits. ${ }^{18}$ They suggested that healthcare professionals and their patients reflect each other's emotional experiences of satisfaction in their tone of voice; in particular, they found a relationship between positive voice tone and patient satisfaction. ${ }^{18}$

Eye contact was another non-verbal signal frequently perceived by patients. Patients appear to be sensitive to this type of non-verbal behaviour as a sign that their GP is listening to them. These observations emphasise the importance of eye contact during medical visits.

Facial expressions, especially smiling, were also commonly perceived by patients. The present study confirms previous findings that the smile is an important component of the doctor-patient interaction. ${ }^{19}$

\section{Implications for future research and clinical practice}

In this study, it was found that non-verbal communication is an important factor by which patients evaluate their interactions with GPs. As shown by this study, GPs should be aware of their own nonverbal behaviours and should monitor them, especially tone of voice, eye contact, and facial expressions.

Other important communication components for patients include touch, interpersonal space, gestures, and GPs' dress. GPs should also take care to create comfortable and appealing environments in which they evaluate patients.

In conclusion, GPs should be trained to better understand their own non-verbal behaviours because this type of communication is an important factor by which patients spontaneously evaluate their interactions with the GP.

Patient perspectives of GPs' non-verbal behaviour provide guidance to improve quality of care. These 
qualitative data can be a starting point for future quantitative studies on patient-doctor communication.

\section{Funding body}

The study was supported by the State Committee for Scientific Research in Poland (2 PO5D 013 30).

\section{Ethics committee}

This study was approved by the Ethics Committee of the Medical University of Bialystok, Poland (R-I-003/262/2005).

\section{Competing interest}

The authors have stated that there are none.

\section{Acknowledgements}

We thank the family doctors and patients involved in this study.

\section{Discuss this article}

Contribute and read comments about this article on the Discussion Forum: http://www.rcgp.org.uk/bjgp-discuss

\section{REFERENCES}

1. Kurtz S, Silverman J, Draper J. Teaching and learning communication skills in medicine. Abingdon, Virginia: Radcliffe Medical Press,1998.

2. Little P, Everitt H, Williamson I, et al. Preferences of patients for patient centred approach to consultation in primary care: observational study. BMJ 2001; 322: 1-7.

3. Kvåle K, Bondevik M. What is important for patient centred care? A qualitative study about the perceptions of patients with cancer. Scand J Caring Sci 2008; 22: 582-589.

4. Roter DL, Frankel RM, Hall JA, Sluyter D. The expression of emotion through nonverbal behavior in medical visits. Mechanisms and Outcomes. J Gen Intern Med 2006; 21: S28-S34.

5. Mast MS. On the importance of nonverbal communication in the physician-patient interaction. Patient Educ Couns 2007; 67: 315-318.

6. Mast MS, Hall JA, Köckner C, Choi E. Physician gender affects how physician nonverbal behavior is related to patient satisfaction. Med Care
2008; 46(12):1212-1218.

7. Pendleton D, Schofield T, Tate P, Havelock P. The consultation: an approach to learning and teaching. Oxford University Press, Oxford, England, 1984: 19-20.

8. Ong LML, De Haes JCJM, Hoos AM, Lammes FB. Doctor-patient communication: a review of the literature. Soc Sci Med 1995; 40: 903-918.

9. Willems S, De Maesschalck S, Deveugele M, et al. Socio-economic status of the patient and doctor-patient communication: does it make a difference? Patient Educ Couns 2005; 56: 139-146.

10. Zimbardo PG, Ruch FL. Psychology and life. (Polish edition). Warszawa: Wydawnictwo Naukowe PWN, 1994.

11. Ellis RB, Gates RJ, Kenworthy N. (eds) Interpersonal communication in nursing. New York, NY: Churchill Livingstone, 1995.

12. Patton MQ. Qualitative research \& evaluation methods. 3rd edn. Thousand Oaks, CA: Sage Publications, 2002.

13. Barbour RS. Checklists for improving rigour in qualitative research: a case of the tail wagging the dog? BMJ 2001; 322:1115-1117.

14. Marcinowicz L, Chlabicz S, Grębowski R. Patient satisfaction with healthcare provided by family doctors: primary dimensions and an attempt at typology. BMC Health Serv Res 2009; 9: 63.

15. Barbour RS. The role of qualitative research in broadening the 'evidence base' for clinical practice. J Eval Clin Pract 2000; 6(2): 155-163.

16. Sandelowski M. Sample size in qualitative research. Res Nurs Health 1995; 18: 179-183.

17. Hall JA, Harrigan JA, Rosenthal R. Nonverbal behaviour in clinician-patient interaction. Appl Prev Psychol 1995; 4: 21-37.

18. Haskard KB, Williams SL, DiMatteo MR, et al. The provider's voice: patient satisfaction and the content-filtered speech of nurses and physicians in primary medical care. J Nonverbal Behav 2008; 32: 1-20.

19. Gorawara-Bhat R, Cook MA, Sachs GA. Nonverbal communication in doctor-elderly patient transactions (NDEPT): Development of a tool. Patient Educ Couns 2007; 66: 223-234. 